\title{
A Transferable Psychological Evaluation of Virtual Reality Applied to Safety Training in Chemical Manufacturing
}

Published as part of the ACS Chemical Health \& Safety joint virtual special issue "Process Safety from Bench to Pilot to Plant" in collaboration with Organic Process Research \& Development and Journal of Loss Prevention in the Process Industries.

Matthieu Poyade, Claire Eaglesham, ${ }^{\S}$ Jordan Trench, ${ }^{\S}$ and Marc Reid*

Cite This: https://dx.doi.org/10.1021/acs.chas.0c00105

Read Online

ABSTRACT: High-profile accidents in the Chemical sectoracross research and manufacturing scales-have provided strong drivers to develop a new benchmark in safety training and compliance. Herein, we describe the design, implementation, and standardized psychological evaluation of virtual reality (VR) applied to process safety training. Through a specific industrial case study, we show that testable learning of complex safetyspecific tasks in VR is statistically equivalent to traditional slidebased video training. However, VR training presents a measurable positive improvement on trainees' perception of overall learning and their feeling of presence in the task during training. It has also been shown that knowledge retention from video lectures can be

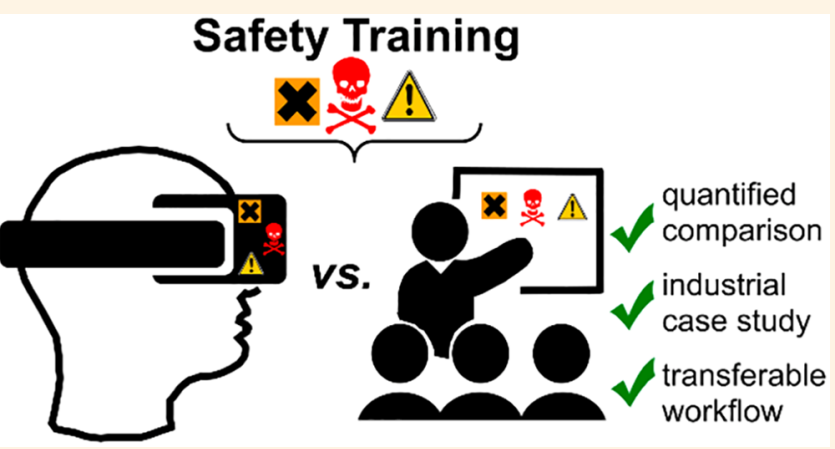
overestimated, if not controlled. Through these results-and our transferable blueprint for robustly assessing any new VR training platform-we envisage a range of technologically enabled efforts to enhance safety performance in both laboratory- and plant-based activities. Implications for physical resource-saving projects are also described.

KEYWORDS: process safety, training, virtual reality, psychology, learning, chemical manufacturing

\section{INTRODUCTION}

1.1. Safety in Chemical Manufacturing. Chemical Manufacturing is changing. With companies in the sector targeting increased process efficiency and safety via efficient data capture, investment in digital solutions has been forecast to reach $\$ 3.2$ billion by 2022 . $^{2}$ Poor safety culture and resulting accidents represent moral, financial, and reputational pain points for any company held accountable. One report collated 70 major accidents across 30 countries in the period 1998$2015{ }^{3}$ showing that Chemical Manufacturing accidents have occurred in France, India, Indonesia, Kenya, Mexico, Pakistan, Poland, Russia, Slovenia, the US, and the UK. The list goes on. The largest ever chemical manufacturing disaster occurred in 1984 in Bhopal, India. Poor site maintenance, substandard chemical understanding, and unsatisfactory emergency response all contributed to a massive gas leak that killed over 2000 people. ${ }^{4}$ The effects of the gas leak led to long-term deaths and injuries over decades.

A broader perspective on safety failures in chemical manufacturing is given by the Centre for Research on the Epidemiology of Disasters (CRED). ${ }^{6}$ Since 1940, the database has captured 165 disasters involving chemical spills and gas leaks, recorded worldwide. ${ }^{6}$ In that time, these disasters have led to the deaths of nearly 4000 people; the number of injuries is 35 times that. The conservative estimate of the number of people affected by those accidents stands at over 1 million (Figure 1). Indeed, the CRED only includes disasters above a minimum threshold of people involved in a particular incident. The full picture is likely much more harrowing. Despite the lucrative nature of chemical and associated manufacturing sectors, 7 the annual cost of injuries on manufacturing sites is staggering. Taking the UK as an example, accidents in manufacturing cost over $£ 627$ million ( $\$ 793$ million, the cost of 13 private jets at $£ 48$ million each). ${ }^{8}$ Two thirds of all reported manufacturing injuries are chemical-related, according to the UK Health \& Safety Executive. ${ }^{8}$ From related process safety concerns in the Oil \& Gas sector, it has been

Received: November 9, 2020 


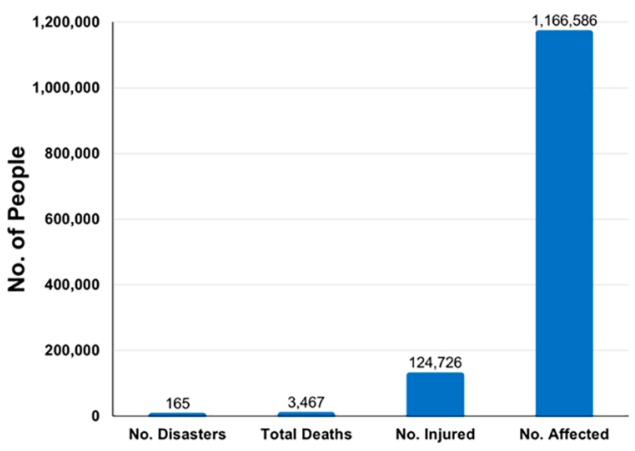

Figure 1. Effect of chemical disasters from gas leaks and spills, 19402020.

estimated that, for every $£ 1$ million ensured against safety accidents, companies will have to account for another $£ 27$ million in uninsured costs of major accidents. ${ }^{9}$ Beyond chemical manufacturing, workplace accidents and lost workdays resulting from accidents are a $£ 5$ billion economic problem for the UK and are linked with broader challenges in post-traumatic stress and other mental health conditions. ${ }^{10}$

From a deeper Chemistry perspective, recent high-profile accidents-on both research and manufacturing scales-have provided strong drivers for culture change and training improvements. ${ }^{11-20}$ While our focus here is on process-scale chemical manufacturing, the similarly severe safety challenges exist on the laboratory scale; such dangers have been extensively reviewed recently. ${ }^{11}$ Through consideration of the emerging digitalization trends and perennial safety challenges in the chemical sector, we envisaged using interactive and immersive virtual reality (VR) $)^{21-23}$ as an opportune technology for developing safety training and accident readiness for those working in dangerous chemical environments.

1.2. Virtual Reality. VR is a branch of computer science that, in applied terms, enables the creation of immersive, interactive, and (where necessary) realistic gamelike experiences in 3D. It has strongly benefited from the advent of mobile technologies and powerful computer graphics and is now seen as an effective disruptive innovation (Figure 2). VR enables interactive and immersive real-time task simulations across a growing wealth of areas, including aerospace, ${ }^{24,25}$ architecture, ${ }^{26}$ construction, ${ }^{27-29}$ manufacturing, ${ }^{30-34}$ video games, ${ }^{23,35}$ arts and humanities, ${ }^{36}$ medicine, ${ }^{23,37-39}$ and education. $^{40-43}$ Of the many areas set to benefit from VR technologies, safe practices for the physical sciences present a significant opportunity. ${ }^{27,29-34,39,44-54,46-54}$ Having stated this, exploration of VR in the Chemistry space remains in relative infancy. ${ }^{54-75}$ In higher education, prelab training in VR has the potential to address these issues giving students multiple attempts to complete core protocols virtually in advance of experimental work, creating the time and space to practice outside of the physical laboratory.

1.3. Safety Educational Challenges. In plant or laboratory work, trainees are required to process information about the operational or experimental technique, while interpreting verbal and written instructions during the laboratory time. Tasks are naturally complex. It has long been demonstrated that such complexity results in learners not engaging and simply following procedures by rote. ${ }^{76-78}$ This has resulted in strategies to present safety information in advance of practical work. ${ }^{79}$ Safety education and research have evolved with technology, moving from videos on cassettes to online formats and simulations. ${ }^{80}$ However, the area is still a challenge, and very recent work has demonstrated that there must be an active link between prelaboratory work and laboratory work in order for the advance work to have impact. ${ }^{81}$ The current status of this area is that the underlying pedagogy is well understood, but education researchers are still seeking ways to hybridize prepractical and practical work. ${ }^{24,82-86}$

1.4. Study Aims. The primary question for this study can be framed as follows: When evaluated on a controlled basis, how do two distinct training methods, (1) VR training and (2) traditional slide training (displayed as a video to ensure the consistency of the provision of training), compare for the same safety-critical task? While some rare studies have investigated the effectiveness of VR in the chemical safety space previously, $^{30,45,47,50,51,87}$ there is, at the time of writing, no consistent approach for looking at the psychological principles of comparative evaluation of VR versus more traditional (nonimmersive) methods of safety training.

Using a complex, safety-critical chemical manufacturing task of broad importance as a case study (see below), we describe herein the digital recreation of a hazardous facility using VR to provide immersive and proactive safety training. We use this case to deliver a thorough statistical assessment of the psychological principles of our VR safety training platform versus the traditional non-immersive training (the latter still being the de facto standard for such live industrial settings). The innovation and central challenge of this investigation are not simply the end-to-end development of a realistic and interactive training platform in VR to replace the non-

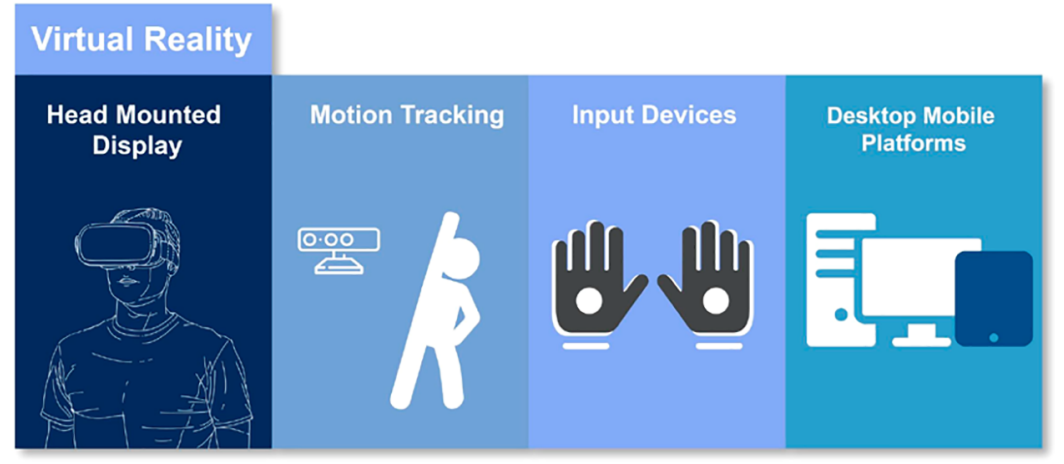

Figure 2. Core components of a virtual reality training setup. 
immersive training. Rather, the key output from this work is a transferrable blueprint of experimental methods that can be applied to formally assess a VR training exercise versus a known non-immersive training variant, where each training method is applied to learning a particular task.

Some of the psychological tools, described in Figure 3 and in detail below, are (at the time of writing) not in common or combined use in Chemistry research.

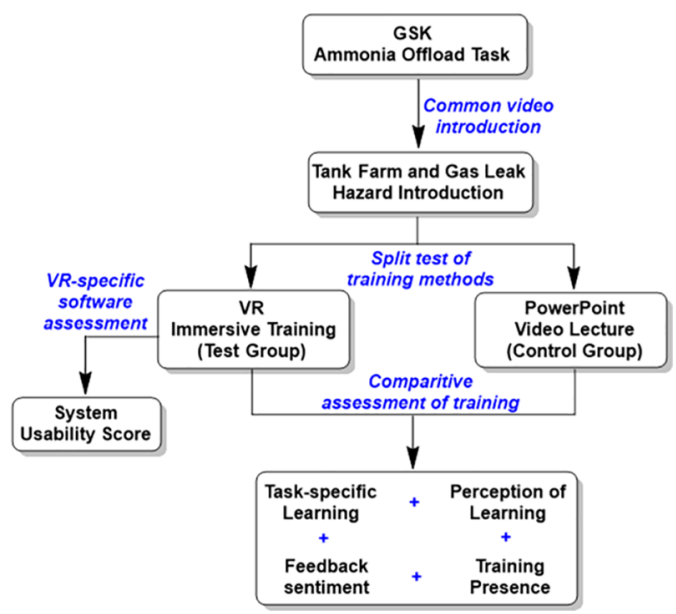

Figure 3. Summarized workflow for safety training case identification and comparative assessment of PowerPoint video versus VR.

\section{METHODS}

Full details of all methods can be found in the Supporting Information.

2.1. Training Procedure. All participants were presented with curated information on (i) the study background, (ii) the study team, (iii) a specific risk assessment and safety notice of the training tasks involved, (iv) a consent form to sign before participation could begin, and (v) a video introduction to tank farms and gas leak hazards. Participants were split randomly into two groups. Each group was assigned one of two specific experimental treatments. In Group 1 (VR group), 17 participants undertook the immersive and interactive safety training for the ammonia offload task in our developed VR platform. In Group 2 (Control group), 11 participants were required to complete the traditional video slide approach to the safety training for the same ammonia offload task. ${ }^{46}$ Video slides faithfully reproduced existing PowerPoint-based GlaxoSmithKline (GSK) training materials, with voiceover narration ensuring a consistent experience for all participants in Group 2. Thus, all participants across both groups were trained within an approximately 45 min controlled time slot. For both VR and video slide training methods, all participants were allowed to view the requisite training materials once only.

2.2. Data Analysis. After completing their training, participants were required to fill in standardized questionnaires which aimed to formally assess 5 measures of their training experiences, detailed below in Sections 2.2.1-2.2.5.

2.2.1. Task-Specific Learning Effect. Participants' posttraining knowledge of the ammonia offload task was assessed in an exam-style test composed of six task-specific openquestions, designed by a GSK staff safety trainer. Questions were based on official GSK training materials and the associated marking scheme. Exam scripts were marked blindly (i.e., anonymized and randomized so that assessors were unaware of participants' identity or group). Moreover, exams were assessed in triplicate, by the 2 study leaders and the GSK EHS staff trainer, using GSK's point-based marking system. Exam marks were then summed, averaged, and normalized into a final percentage grade for each participant.

2.2.2. Perception of Learning Confidence. How well participants perform on a training exam and how they feel about the overall learning experience are not the same thing. ${ }^{88}$ Participant experiences were assessed through 8 bespoke statements, which were specifically designed for the assessment of both training conditions. Participants rated their agreement with these statements on a typical 5-point Likert scale (1, Strongly Disagree; 2, Disagree; 3, Neutral; 4, Agree; 5, Strongly Agree). Statements looked at aspects of the learning experience that are proxies for effectiveness, such as the perception of having acquired knowledge about the task, the usefulness of the training method within the task-specific context and beyond, and the confidence gained to later perform the safetycritical task alone.

2.2.3. Sense of Perceived Presence. "Presence" can be defined as the depth of a user's imagined sensation of "being there" inside the training media they are interacting with. It is connected but not identical to the sensation of physical immersion generated by the technical assets that deliver the experience. Presence is compared to the level of psychological involvement experienced in one, two, or more training media; in our case, between VR and video slides. Although there is a lack of consensus about the effect of users' perceived presence to support learning in virtual environments, ${ }^{89,90}$ it has been shown that presence can contribute to increased task performance, knowledge, and skills development, within and beyond virtual training environments. ${ }^{91,92}$ The independent television corporation (ITC)-Sense of Presence Inventory ${ }^{93}$ is a cross-media presence questionnaire for the quantification of the user's psychological involvement within, for instance, a training environment. Users answer how much they agree with a series of statements, using a typical 5-point Likert scale. Overall, the presence questionnaire captures four dimensions: Spatial Presence; Engagement; Ecological Validity; and Negative Effects (all defined in Figure 4).

2.2.4. Usability. From the field of human-computer interaction, the System Usability Scale (SUS) has become the industry standard for the assessment of system performance and fitness for the intended purpose. ${ }^{94-97}$ Across 10 carefully chosen statements, a user answers their level of agreement on a Likert scale, resulting in a score out of 100 that

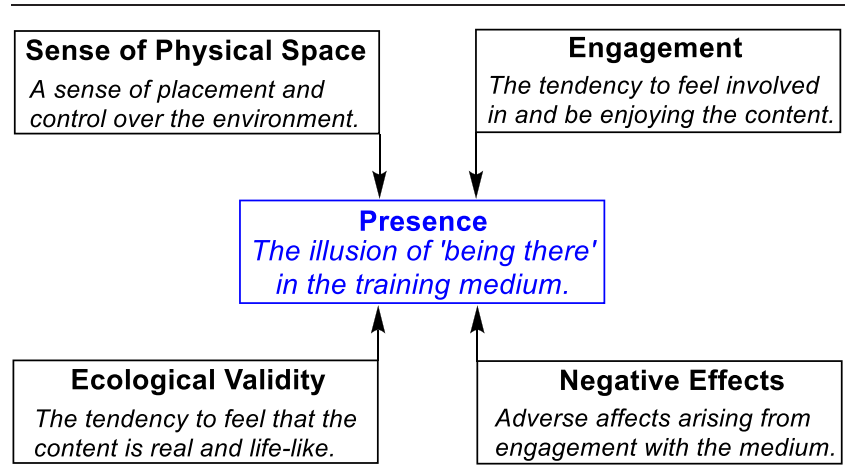

Figure 4. Four components of presence to measure a user's involvement in the training. 
can be converted to a grade A-F (Figure 5). In our study, the SUS was used to evaluate the subjective usability of our VR training system.

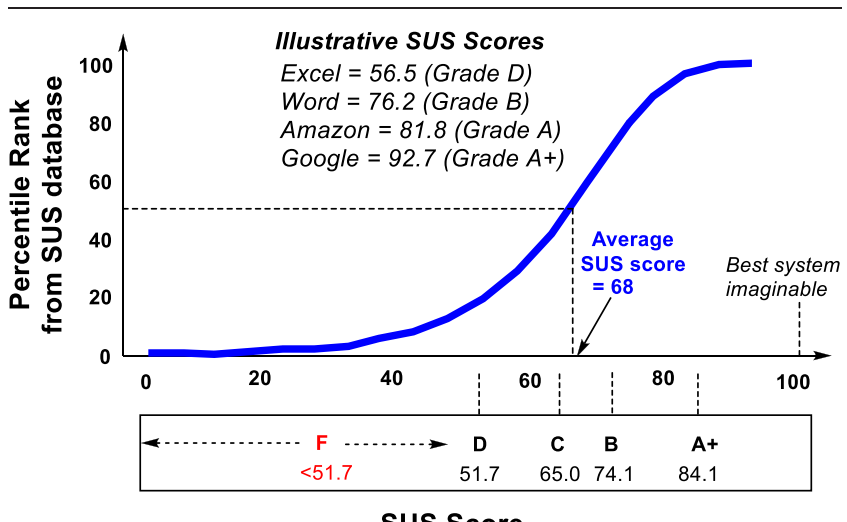

Figure 5. System Usability Score (SUS) to measure a computer system's fitness for purpose.

For comparisons between the VR and Control groups across (Section 2.2.1) task-specific learning, (Section 2.2.2) sense of perceived learning confidence, and (Section 2.2.3) presence, a series of Mann-Whitney $U$ tests were conducted, using PSPP, ${ }^{98}$ to determine whether there were statistically significant differences between the VR and Control groups across these measurable dimensions.

2.2.5. Sentiment Analysis. To assess consistency between the conclusions drawn from the statistical analysis of formal survey responses in Sections 2.2.1-2.2.4 and the verbal participant feedback on their training experiences, focus group interviews were transcribed into text-based scripts. The resulting transcripts of participant feedback-from both the VR and non-VR safety training groups-were used with the Linguistic Inquiry and Word Count (LIWC, pronounced "Luke") program. ${ }^{99-101}$ Therein, the unedited and wordordered text structure (the corpus) was analyzed against the LIWC default dictionary, outputting a percentage of words fitting psychological descriptors. Most importantly for this study, the percentage of words labeled with positive or negative affect (or emotion) were captured to enable quantifiable comparison between the VR and non-VR feedback transcripts.

\section{RESULTS}

3.1. Case Study Implementation. To focus our safety training developments on a chemical manufacturing environment presenting major accident risks, we collaborated with health and safety professionals at GlaxoSmithKline's (GSK's) antibiotic manufacturing plant in Irvine, Scotland. The site primarily focuses on the preparation of amoxycillin and clavulanic acid, which together are in global demand on the multitonne scale. ${ }^{102,103}$ From a safety perspective, the GSK site presents many trip, vehicle, chemical, and operational hazards. Indeed, the site has suffered two notable accidents in its recent history. ${ }^{104,105}$

Chief among all such safety concerns on the GSK site is the use of liquid ammonia to control $\mathrm{pH}$ in some of the synthetic processes. Far from being a niche problem on a single plant, ammonia is at the heart of the evolving renewables economy, ${ }^{106}$ and over $\$ 60$ billion worth of the gas is produced globally every year. ${ }^{107}$ With regards to process safety, ammonia leakages and losses of containment have led to severe moral, legal, and financial consequences on numerous occasions. ${ }^{104,105,108-120}$ More broadly, chemical disasters caused by gas leaks and spills have killed over 3000 people between 1940 and 2020 (Figure 1). ${ }^{6}$

The ammonia tank farm on the GSK Irvine site hosts three large cylinders in which several tens of tonnes of ammonia are stored at any one time (Figure $6 \mathrm{a}, \mathrm{b}$ ). The ammonia is brought onto the site on a daily basis via a vehicular tanker. The highly dangerous gas is then securely offloaded from the vehicle into the site storage tanks. During the offloading process, a tank farm operator works in collaboration with the vehicle driver who is responsible for connecting the vehicle to the on-site tanks. Together, the operator and vehicle driver complete a series of complex valve turns, pressure checks, personal protective equipment ( $\mathrm{PPE}$ ) arrangements, area clearance,

a.
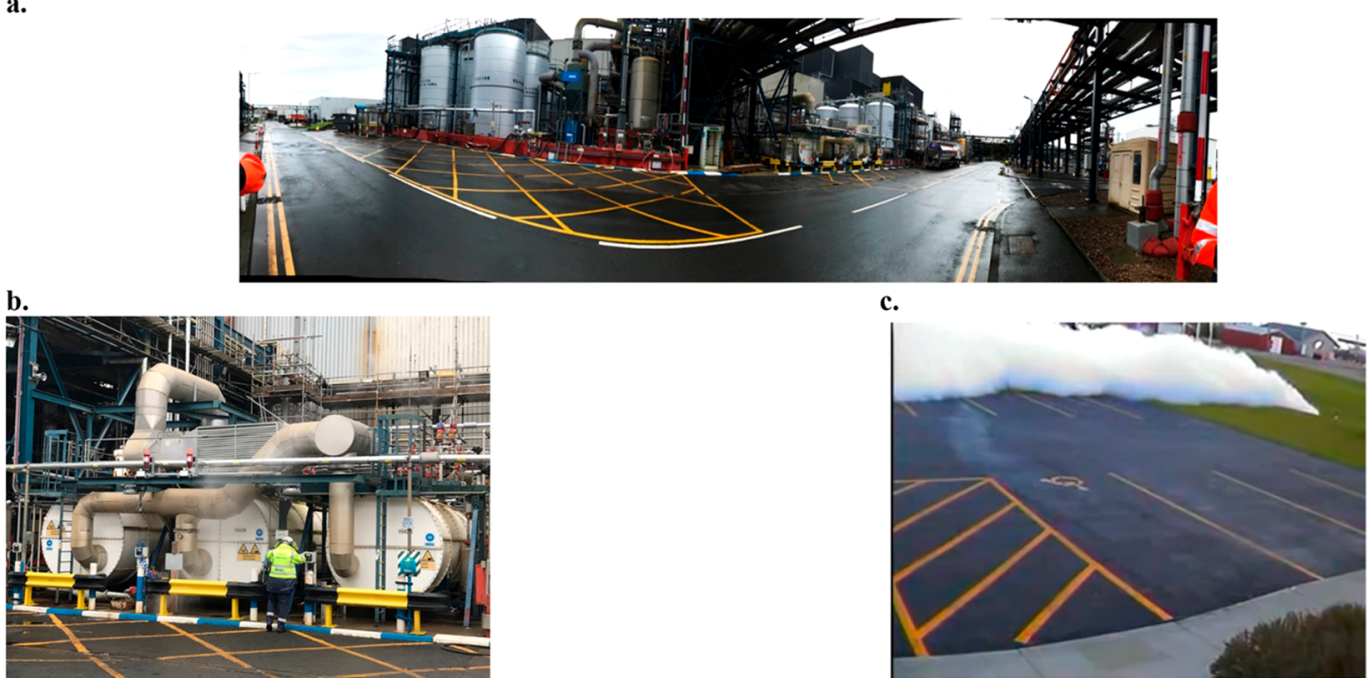

Figure 6. Representative images of the GSK manufacturing site. (a) Panoramic view of the ammonia tank farm and immediate surroundings. (b) Close-up of the ammonia tanks, showing scale relative to a human worker. (c) CCTV footage showing the result of a massive loss of ammonia containment on a similar manufacturing site. ${ }^{121}$ 
a.

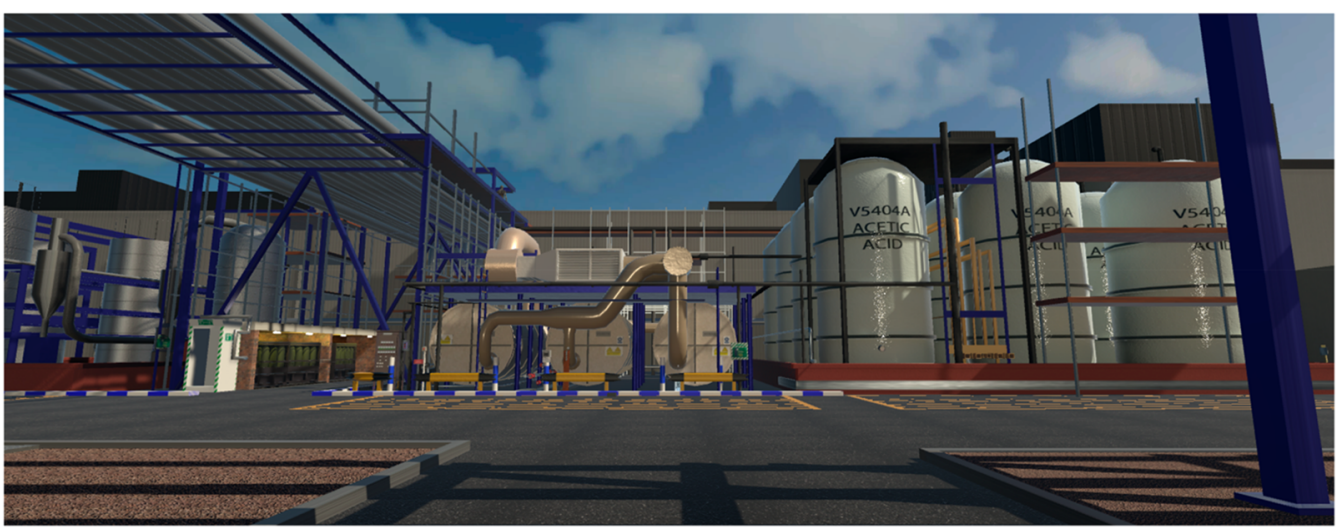

b.

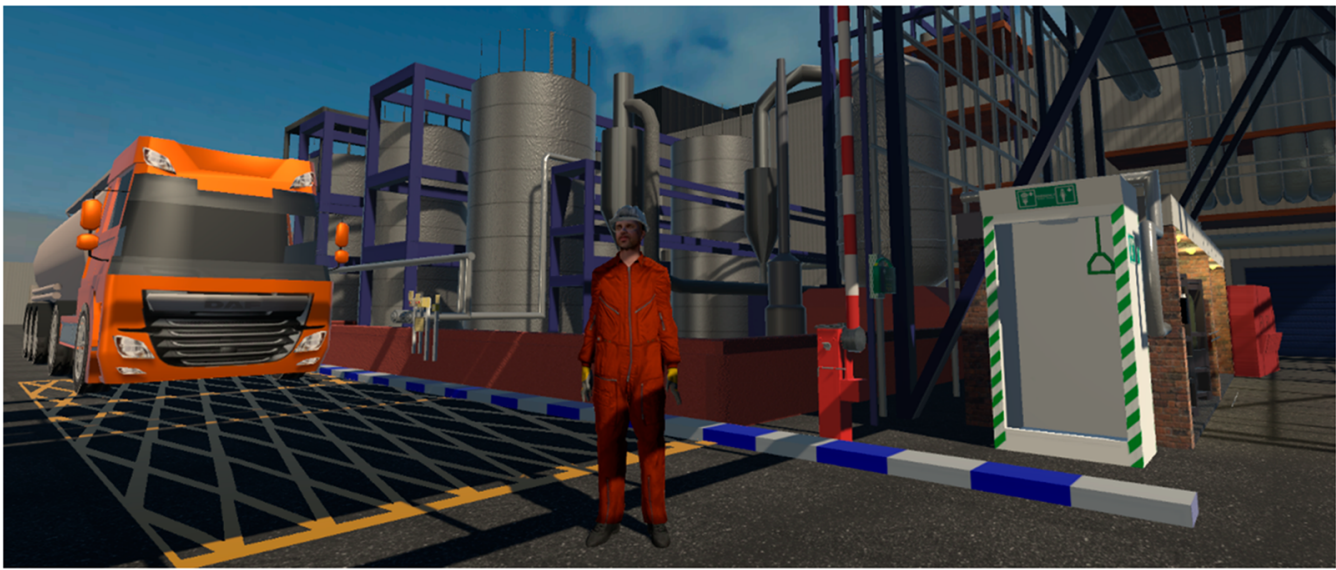

c.

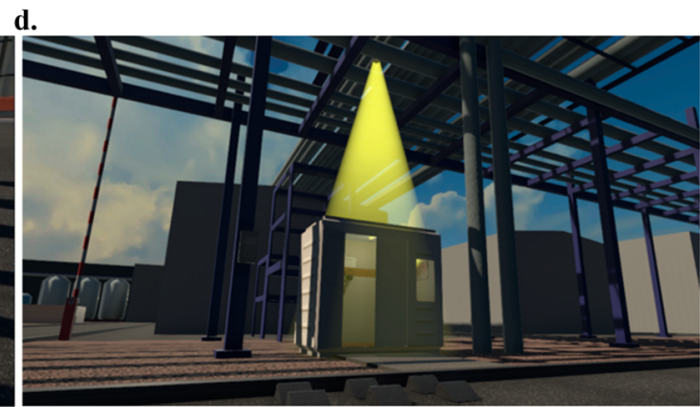

Figure 7. Representative images of the VR safety training platform. (a) Full view of the "digital twin" model of the ammonia tank farm on the GSK manufacturing site. (b) View of avatar wearing PPE, ammonia-carrying vehicular tanker, road barrier, and emergency shower-all representing areas of trainee interaction. (c) Virtual tablet providing trainees with assisted stepwise walkthrough of standard operating procedures, normally confirmed to verbose paperwork. (d) Example of lighting assistance, guiding new trainees to the correct site locations at a given point in the operating procedure. The example shows a PPE hut wherein trainees interact with and don PPE equipment needed for the main ammonia offload tasks.

road barrier assembly, wind checks, and communications with managerial staff. In sum, the ammonia offload task at the GSK manufacturing site is a highly complex procedure that presents clear risks for loss of gas containment, ${ }^{120}$ a major accident to site staff, injury to the local population, and irreversible damage to the environment (exemplified in Figure 6c). ${ }^{110,121}$

Developing a VR platform for GSK's ammonia offload task presented the opportunity to solve two key safety-related challenges. First, we hypothesized that an immersive safety training protocol would enhance existing classroom-based methods used routinely by industrial safety staff. In this way, VR would enable trainees to take a virtual tour of the dangerous worksite and interactively follow official standard operating procedures (SOPs), eliminating any temptation to skim-read, lose concentration, or suffer undue loss of information retention. Second, the development of a VR training platform would enable staff to train on their own, off site, before commencing mandatory and resource-intensive "buddy" training on site. This digital pretraining approach would thus present the opportunity for trainees to gain confidence and familiarity in their dangerous work task before accepting the risk of training on the real manufacturing site.

3.2. Building the Ammonia Tank Farm's Digital Twin. Efforts to recreate the GSK site digitally began with a full site tour, safely building a photographic, videographic, and audio inventory of the site. A site map was used as a mask over a plane in 3DSMax, an Autodesk modeling platform, to faithfully create to scale and extrude the topology of the site. 
a.

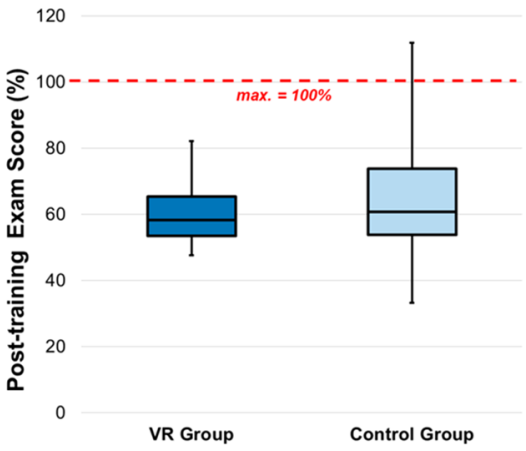

c.

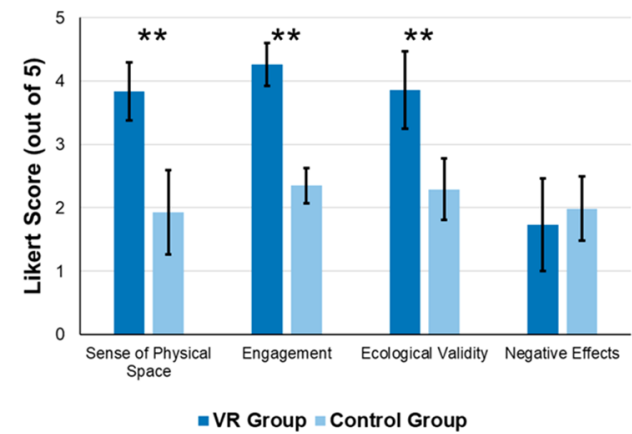

b.

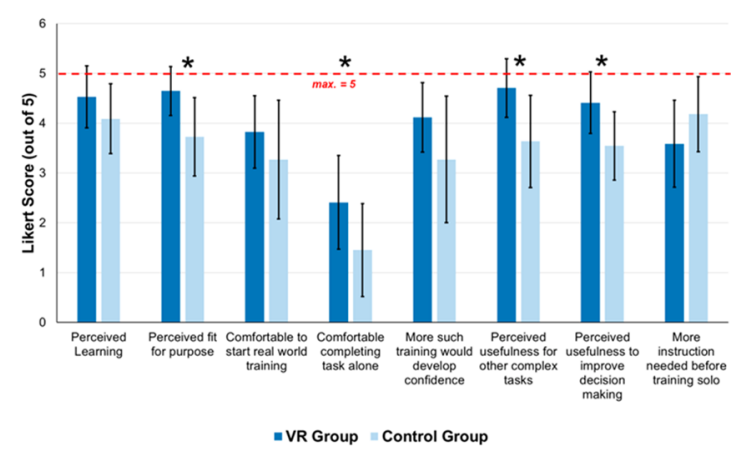

d.

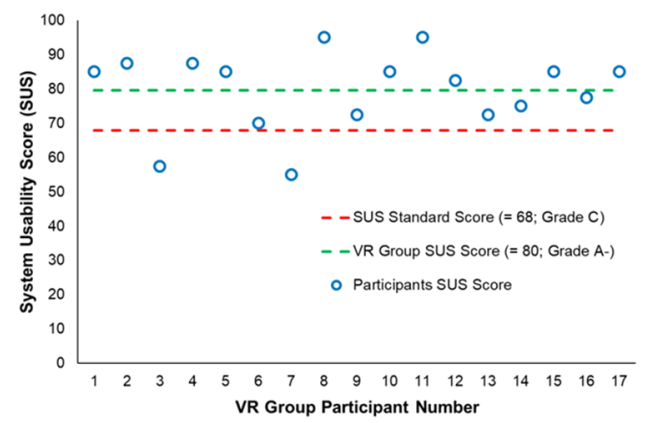

Figure 8. Summary of the psychological assessment of VR versus non-VR (video slide-based) safety training. (a) Task-specific learning effect. (b) Perception of learning confidence. (c) Assessment of training presence. (d) VR system usability score. In parts b and c, $*$ and $* *$ represent statistically significant results with $p<0.05$ and $p<0.001$, respectively.

Photographic, video, and audio material were then used to digitally build the major architectural structures in the aforementioned modeling platform and progressively reconstruct the pipework and the other assets that could be found across the site (Figure 7a,b). Photographic material was processed with Adobe Photoshop Suite, an image editing platform, to generate a photorealistic texturing of the different components within the digital environment; whereas audio recordings were used to create an audio spatialized digital environment. The digital environment was exported into the Unity Game engine, in which the HTC Vive and Leap Motion Controller plugins were used to implement the different interactions that were required throughout the training. The training procedure was implemented on the basis of state machine principles, with binary outputs. The user must perform a task action correctly before the system allows performing the next task step. The user was able to consult the upcoming step sequence on a digital tablet that was attached to one of their virtual hands (Figure 7c). Although the system was not providing any feedback associated with incorrect user actions, the user could request help to the system, in the form of a graphical light cue which highlighted the area where the current task step was meant to be carried out (Figure $7 \mathrm{~d}$ ).

To marry the new training developments with existing safety protocols, we collected and integrated GSK's SOPs, classroom training materials, and descriptions of emergency procedures into VR-based instructions (Figure 7).

3.3. Safety Training Evaluation. Having created a bespoke VR safety training platform for the GSK ammonia offloading task, the value of this modern training approach could be formally assessed versus GSK's existing training protocols. Crucial to this assessment was the bringing together of experimental methods which focus on psychological principles that are not yet commonly practiced in chemical health and safety training assessment (Figure 3). All results presented below are summarized in Figure 8 and Table 1.

3.4. Task-Specific Learning Effect. Task-specific learning for the ammonia offload task was assessed using a questionnaire built upon official GSK training materials and marking schemes. Overall, test scores from the Control group $(M=62.5 \pm 16.3 \%, M d n=58.3)$ and the VR group $(M=59.9$ $\pm 8 \%, \mathrm{Mdn}=60.7)$ showed no statistical difference between groups $\left[U\left(N_{\mathrm{VR}}=17, N_{\text {nonVR }}=11\right)=80.5, z=-0.61, p=\right.$ $0.541]$. However, there was tighter distribution around the mean score for the VR group versus the Control group. See Figure 8a.

3.5. Perception of Learning Confidence. Participants' perceived confidence of having gained new knowledge was assessed using a questionnaire composed of 8 statements, probing multiple aspects of the learning experience. Of these 8 questions, 4 drew out statistically significant differences between the training groups: perceived fit for purpose $\left[U\left(N_{\mathrm{VR}}=17, N_{\text {nonVR }}=11\right)=32.5, z=-3.17, p<0.05\right]$; comfortable completing the task alone $\left[U\left(N_{\mathrm{VR}}=17, N_{\text {nonVR }}=\right.\right.$ 11) $=36.5, z=-2.84, p<0.05]$; perceived usefulness for other complex task $\left[U\left(N_{\mathrm{VR}}=17, N_{\text {nonVR }}=11\right)=28.5, z=-3.36, p<\right.$ $0.05]$; and perceived usefulness to improve decision $\left[U\left(N_{\mathrm{VR}}=\right.\right.$ $\left.\left.17, N_{\text {nonVR }}=11\right)=36.5, z=-2.96, p<0.05\right]$.

Within a $95 \%$ confidence limit, the VR training method was perceived by participants to be significantly more fit for training purpose than video slides. VR also gave participants confidence that they could next perform the safety task alone. Moreover, participants rated VR as having more potential than traditional slides for helping train in other complex tasks and to 
improve decision making skills (Figure 8b). Overall, participants from the VR group felt more confident and prepared for on-site training than those from the Control group.

3.6. Sense of Perceived Presence. The Sense of Presence $^{93}$ questionnaire was used to gauge participants' overall feeling of training involvement across four key dimension (see Figure 4 and Section 2.2.3). Results show that participants from the VR group reported experiencing a higher sense of presence than those from the Control group. Highly significant differences between the training groups were found for three of the four presence factors: sense of physical space $\left[U\left(N_{\mathrm{VR}}=17, N_{\mathrm{nonVR}}=11\right)=0.5, z=-4.38, p<0.001\right]$, engagement $\left[U\left(N_{\mathrm{VR}}=17, N_{\mathrm{nonVR}}=11\right)=0, z=-4.41, p<\right.$ $0.001)]$, and ecological validity $\left[U\left(N_{\mathrm{VR}}=17, N_{\text {nonVR }}=11\right)=3\right.$, $z=-4.28, p<0.001]$. On the fourth dimension, negative effects, participants from the Control group reported experiencing more negative effects than those from the VR group, but the result was not statistically different (Figure 8c). Further insight on the comparative negative effects of each training method came from post-training focus groups and sentiment analysis (detailed below).

3.7. Usability of the VR Training Platform. The System Usability Scale (SUS) ${ }^{95}$ was used to assess the effectiveness, intuitiveness, and satisfaction with which participants were able to achieve the task objectives within the VR environment. The average SUS score recorded was $79.559(\sim 80$, or grade A-), which placed our VR training platform on the edge of the top $10 \%$ of SUS scores (see Figure 5 for context). The SUS result indicated an overall excellent experience for participants in the VR group.

Beyond the SUS, participants were also asked a series of questions (scored on a 5-point Likert scale, 1 being Strongly Disagree and 5 being Strongly Agree) in order to more fully explore their VR safety training experience. In sum, the VR participants strongly agreed that they had received a sufficient amount of instructions to support them throughout their training $(4.5 \pm 0.8)$.

They disagreed with any notion that the VR experience was too long $(1.6 \pm 0.7)$ and did not think it was too short $(2.5 \pm$ 1.1). Participants agreed that the simulation was stable and smooth $(3.9 \pm 1.2)$ and disagreed that it was in any way jaggy $(2.3 \pm 0.8)$. Hand-based interactions with the VR environment were agreed to be relatively intuitive $(3.8 \pm 1.3)$, and the headmounted display was found to provide agreeable comfort for the duration of the training $(4.0 \pm 0.9)$.

3.8. Sentiment Analysis of Participant Feedback. In the final part of our study, we aimed to corroborate the formal statistical analysis against a quantitative analysis of open participant feedback. Using the text-based transcripts from both the Control and VR group participant feedback, the Linguistic Inquiry and Word Count (LIWC) tool ${ }^{101}$ provided further insight based on the emotional sentiment hidden in the plain text. VR participants were found to use more positively emotive words ( $4.2 \%$ of the VR training feedback corpus) versus the Control group ( $2.1 \%$ of the video training feedback corpus). More broadly, the VR group displayed a more positive emotive tone and used fewer negatively emotive words than the Control group (Table 1).

3.9. Control Group Behavior. In addition to assessing the VR versus video slide training groups, a third group was assessed, wherein participants watched the training video (just like the main Control group) but without any restriction on
Table 1. LIWC-Enabled Sentiment Analysis of Participant Feedback Transcripts

\begin{tabular}{|c|c|c|c|}
\hline $\begin{array}{c}\text { LIWC } \\
\text { variable }\end{array}$ & brief description & $\begin{array}{l}\text { VR- } \\
\text { group }\end{array}$ & $\begin{array}{l}\text { non-VR } \\
\text { group }\end{array}$ \\
\hline word count & no. of words in the transcript & 1493 & 984 \\
\hline $\begin{array}{l}\text { emotional } \\
\text { tone }\end{array}$ & $\begin{array}{l}\text { difference between positive and negative } \\
\text { words }(<50=\text { negative })\end{array}$ & 83.1 & 24.2 \\
\hline $\begin{array}{l}\text { positive } \\
\text { emotion }\end{array}$ & $\%$ positive words (e.g., love, nice, sweet) & $4.2 \%$ & $2.1 \%$ \\
\hline $\begin{array}{l}\text { negative } \\
\text { emotion }\end{array}$ & $\%$ negative words (e.g., hurt, nasty, ugly) & $1.1 \%$ & $2.2 \%$ \\
\hline
\end{tabular}

training video usage. Interestingly, during the task-specific post-training exam, this third group was found to repeatedly rewatch the video training footage at key timestamps that contained answers to the task-specific questionnaire used to measure learning. Under these conditions, this third group $(83.5 \pm 1.4 \%$ per exam question) appeared to have superior learning versus VR ( $59.9 \pm 8.0 \%$ per question). However, this was a false result uncovered by the observation of participants in this third group rewatching the video while answering the test questionnaire. This behavior was captured in the greater similarity between test answers for the group, versus the wider diversity of answering wording captured for participants in the VR and Control groups that were only allowed to view training footage once through. All data pertaining to this additional observation are presented in the Supporting Information.

\section{DISCUSSION}

Overall, using our transferable assessment workflow, the statistical survey analysis showed that task-specific learning was equivalent for VR and non-VR groups. This suggests that the VR training in that specific context is not detrimental to learning and appears to be as effective as the traditional training modality but, crucially, with improved user investment in the training experience. However, the distribution difference between both training modalities suggests that the VR training provided a more consistent experience across participants than watching video slides, but more evaluation would be required to verify this.

In addition, perceived learning confidence and sense of perceived presence were reported to be all significantly better in VR over the non-VR group. The reported differences in perceived learning confidence between participants from both groups suggest that those from the VR group, despite having acquired a similar amount of knowledge, were feeling more assured about the applicability of that knowledge. These findings thus suggest that the VR training resulted in a more engaging and psychologically involving modality able to increase participants' confidence in their own learning. Further research will also aim to explore the applicability and validation of the perceived learning confidence questionnaire introduced in this investigation.

Additionally, VR system usability was quantifiably excellent, according to the SUS score and feedback text sentiment analysis.

Although our experimental data demonstrate the value of the VR modality for health and safety training in chemical manufacturing settings, the sampling, and more particularly the variation in digital literacy among participants, may be a limitation to the study. Therefore, future research should explore the training validity of the proposed approach involving a homogeneously digitally literate cohort of 
participants to more rigorously measure knowledge development between experimental conditions.

4.1. Implications for Chemical Health and Safety Training. By requiring learners to complete core protocols virtually in advance of real work, VR pretask training has the potential to address issues of complex learning, knowledge retention, training turnover times, and safety culture enhancements. Researchers in the Chemical and Petrochemical Sciences operate across an expansive range of sites, from small laboratories to pilot plants and refineries. Therefore, beyond valuable safety simulations and training exercises, outputs from this work are envisaged to breed applications where remote virtual or augmented assistance can alleviate the significant risks to staff on large-scale manufacturing sites.

4.2. Optimizing Resource-Intensive Laboratory Spaces. As a space category in buildings, chemistry laboratories are significantly more resource-intensive than office or storage spaces. ${ }^{64,122}$ The ability to deliver virtual chemical safety training, as demonstrated herein, could serve toward the consolidation and recategorization, minimizing utility and space expenditure threatening sustainability. ${ }^{123}$ By developing the new Chemistry VR laboratories, high utility bills associated with running physical chemistry laboratories could potentially be significantly reduced.

4.3. Bridging Chemistry and Psychology. By bringing together psychological and computational assessments of safety training, the workflow applied herein could serve as a blueprint for future developments in this emerging multidisciplinary research domain. Indeed, the need to bring together chemical and psychological skill sets was highlighted in the aforementioned safety review by Trant and Menard. ${ }^{11}$

\section{CONCLUSIONS}

Toward a higher standard of safety training and culture, we have described the end-to-end development of a VR safety training platform deployed in a dangerous chemical manufacturing environment. Using a specific process chemical case study, we have introduced a transferable workflow for the psychological assessment of an advanced training tool versus traditional slide-based safety training. This same workflow could conceivably be applied to training developments beyond safety.

Comparing our VR safety training versus GSK's established training protocols, we found no statistical difference in the task-specific learning achieved in VR versus traditional slidebased training. However, statistical differences, in favor of VR, were found for participants' positive perception of learning confidence and in their training presence (or involvement) in what was being taught. In sum, VR training was shown to help participants invest more in their safety training than in a more traditional setting for training.

Specific to the VR platform itself, the standard System Usability Scale (SUS) found that our development ranked as "A-" or $80 \%$, placing it toward an "excellent" rating and well within the level of acceptance to deliver competent training.

Our ongoing research in this space is now extending into related chemical safety application domains.

\section{ASSOCIATED CONTENT}

\section{SI Supporting Information}

The Supporting Information is available free of charge at https://pubs.acs.org/doi/10.1021/acs.chas.0c00105.
LIWC2015 results (XLSX)

Further details of VR hardware, software, and data collection (PDF)

All anonymized raw data (XLSX)

\section{AUTHOR INFORMATION}

\section{Corresponding Author}

Marc Reid - WestCHEM Department of Pure \& Applied Chemistry, University of Strathclyde, Glasgow G1 1XL, United Kingdom; (1) orcid.org/0000-0003-4394-3132;

Email: marc.reid.100@strath.ac.uk

\section{Authors}

Matthieu Poyade - School of Simulation and Visualisation (SimVis), Glasgow School of Art, Glasgow G51 1EA, United Kingdom

Claire Eaglesham - School of Simulation and Visualisation (SimVis), Glasgow School of Art, Glasgow G51 1EA, United Kingdom

Jordan Trench - School of Simulation and Visualisation (SimVis), Glasgow School of Art, Glasgow G51 1EA, United Kingdom

Complete contact information is available at:

https://pubs.acs.org/10.1021/acs.chas.0c00105

Author Contributions

${ }^{\S}$ C.E. and J.T. contributed equally.

Notes

The authors declare the following competing financial interest(s): MR is a director shareholder in Pre-Site Safety Ltd.

\section{ACKNOWLEDGMENTS}

We thank the Advanced Forming Research Centre (AFRC, now part of the National Manufacturing Institute Scotland) for Route to Impact funding (2017/18 and 2018/19). Within the AFRC, we thank David Grant, Lynne McIntosh, and Wenjuan Wang for their supportive discussions. We also thank Craig Henderson, Anna Jamieson, Andrew Gunn, and their respective teams at GlaxoSmithKline Irvine for their open support and appraisal of this research programme. For helping educational review of the early concepts hypothesized for this work, thanks also go to Professor Michael K. Seery (University of Edinburgh). M.R. thanks the Leverhulme Trust for fellowship funding (ECR-2016-264).

\section{REFERENCES}

(1) Chemicals 4.0-The Era of Digital Process Production: Uptake in the Deployment of Digital Infrastructure in Chemical Plants to Unleash New Growth Opportunities, 2017. https://www.businesswire.com/ news/home/20170607005651/en/Chemicals-4.0---The-Era-ofDigital-Process-Production---Uptake-in-the-Deployment-of-DigitalInfrastructure-in-Chemical-Plants-to-Unleash-New-GrowthOpportunities---Research-and-Markets.

(2) Thieven, S. V.; Cliton, A.; Mahto, M.; Sniderman, B.; Van Thienen, S.; Clinton, A.; Mahto, M.; Sniderman, B. Industry 4.0 and the Chemicals Industry Catalyzing Transformation through Operations Improvement and Business Growth; Deloitte Univeristy Press, 2016; pp $1-24$.

(3) Koteswara Reddy, G.; Yarrakula, K. Analysis of Accidents in Chemical Process Industries in the Period 1998-2015. Int. J. ChemTech Res. 2016, 9 (4), 177-191.

(4) Yang, M.; Khan, F.; Amyotte, P. Operational Risk Assessment: A Case of the Bhopal Disaster. Process Saf. Environ. Prot. 2015, 97, 7079 . 
(5) Taylor, A. Bhopal: The World's Worst Industrial Disaster, 30 Years Later. The Atlantic, 2014.

(6) EM-DATIThe international disasters database. https://www. emdat.be/ (accessed July 7, 2020).

(7) Landscape of the European Chemical Industry 2020; Brussels, 2018. http://www.chemlandscape.cefic.org/wp-content/uploads/ combined/fullDoc.pdf (accessed January 5, 2020).

(8) Manufacturing statistics in Great Britain, 2019. http://www.hse. gov.uk/statistics/industry/construction.pdf (accessed November 11, 2020).

(9) Cairns, W. J.; Wilkie, A. G.; Kemp, A. G.; Vercoe, J.; Vinogradov, S.; Side, J. C.; Gorml, K. Encompassing the FuturelExecutive Summaries: Environment, Health \& Safety Performance Management, 1st ed.; ICOE Research Ltd, 2017.

(10) Health and safety at work Summary statistics for Great Britain, 2018. https://www.hse.gov.uk/statistics/overall/hssh1718.pdf (accessed July 10, 2020).

(11) Ménard, A. D.; Trant, J. F. A Review and Critique of Academic Lab Safety Research. Nat. Chem. 2020, 12 (1), 17-25.

(12) Kemsley, J. N. 10 years after Sheri Sangji's death, are academic labs any safer? Chem. Eng. News 2018, 97 (1).

(13) Rebecca Trager. Injured postdoc sues University of Hawaii over lab explosion $\mid$ News|Chemistry World. https://www.chemistryworld. $\mathrm{com} /$ news/injured-postdoc-sues-university-of-hawaii-over-labexplosion/2500356.article\#/ (accessed July 23, 2020).

(14) Kiehm, H. M.; Meredith, D. Summons to Answer Civil Complaint. Law Office of Harrison M. Kiehn, Hawai'i (USA), 2017. https://protect.iu.edu/labnotes-archive/W2016/2017-01-09-uhawaii-civil-complaint.pdf.

(15) Vidal, S. Safety First: A Recent Case of a Dichloromethane Injection Injury. ACS Cent. Sci. 2020, 6 (2), 83-86.

(16) Eighmy, T.; Schovanec, L.; Young, A.; Martin, J.; Casadonte, D. J. Ten Years After the Texas Tech Accident: Part I: A Historical Retrospective. J. Chem. Health Saf. 2020, 27 (2), 105-113.

(17) Manolo Morales. UH researcher who lost an arm in lab explosion fighting two battles. https://www.youtube.com/watch?v= h9weMvFxhx8 (accessed July 23, 2020).

(18) Ayi, H.-R.; Hon, C.-Y. Safety Culture and Safety Compliance in Academic Laboratories: A Canadian Perspective. J. Chem. Health Saf. 2018, 25 (6), 6-12.

(19) Walters, A. U. C.; Lawrence, W.; Jalsa, N. K. Chemical Laboratory Safety Awareness, Attitudes and Practices of Tertiary Students. Saf. Sci. 2017, 96, 161-171.

(20) Dunn, A. L.; Payne, A.; Clark, P. R.; McKay, C.; Williams, G. D.; Wheelhouse, K.; Arendt, K.; Dixon, F.; Shilcrat, S. Process Safety in the Pharmaceutical Industry: A Selection of Illustrative Case Studies. J. Chem. Educ. 2020, in press. DOI: 10.1021/acs.jchemed.0c00115.

(21) LaValle, S. M. Virtual Reality, 1st ed.; Cambridge University Press, 2017.

(22) Parisi, T. Learning Virtual Reality; O’Reilly Media, Inc., 2015.

(23) Ma, M.; Oikonomou, A.; Oikonomou, A. Serious Games and Edutainment Applications; Ma, M. Springer International Publishing: Cham 2017, II, 702.

(24) Shi, Z.; McGhan, C. L. R. Affordable Virtual Reality Setup for Educational Aerospace Robotics Simulation and Testing. J. Aerosp. Inf. Syst. 2020, 17 (1), 66-69.

(25) Mu, Z.; Liu, M.; Tan, Z. On the Interactive Display of Virtual Aerospace Museum Based on Virtual Reality. Proceedings - 2018 International Conference on Robots and Intelligent System, ICRIS 2018 2018, 144-146.

(26) Liu, Y.; Castronovo, F.; Messner, J.; Leicht, R. Evaluating the Impact of Virtual Reality on Design Review Meetings. J. Comput. Civ. Eng. 2020, 34 (1), 04019045.

(27) Kiral, I. A.; Comu, S.; Kavaklioglu, C. Enhancing the Construction Safety Training By Using Virtual Environment: VSafe. Sth Int. Constr. Spec. Conf. 2015, 161-1-161-9.

(28) Wang, P.; Wu, P.; Wang, J.; Chi, H.-L.; Wang, X. A Critical Review of the Use of Virtual Reality in Construction Engineering
Education and Training. Int. J. Environ. Res. Public Health 2018, 15 (6), 1204.

(29) Cardoso, A.; Prado, P. R.; Lima, G. F. M.; Lamounier, E. A Virtual Reality Based Approach to Improve Human Performance and to Minimize Safety Risks When Operating Power Electric Systems. In Advances in Intelligent Systems and Computing; Springer Verlag, 2017; Vol. 495, pp 171-182. DOI: 10.1007/978-3-319-41950-3_15.

(30) Nazir, S.; Manca, D. How a Plant Simulator Can Improve Industrial Safety. Process Saf. Prog. 2015, 34 (3), 237-243.

(31) Ouyang, S.-G.; Wang, G.; Yao, J.-Y.; Zhu, G.-H.-W.; Liu, Z.-Y.; Feng, C. A Unity3D-Based Interactive Three-Dimensional Virtual Practice Platform for Chemical Engineering. Comput. Appl. Eng. Educ. 2018, 26 (1), 91-100.

(32) Patle, D. S.; Manca, D.; Nazir, S.; Sharma, S. Operator Training Simulators in Virtual Reality Environment for Process Operators: A Review. Virtual Real. 2019, 23 (3), 293-311.

(33) Berg, L. P.; Vance, J. M. Industry Use of Virtual Reality in Product Design and Manufacturing: A Survey. Virtual Real. 2017, 21 (1), 1-17.

(34) Zhang, H.; He, X.; Nie, B.; Mitri, H. A New Virtual Reality Training System for Underground Coal Mines. 3rd Int. Symp. Mine Saf. Sci. Eng. 2016, 223.

(35) Pallavicini, F.; Pepe, A.; Minissi, M. E. Gaming in Virtual Reality: What Changes in Terms of Usability, Emotional Response and Sense of Presence Compared to Non-Immersive Video Games? Simul. Gaming 2019, 50 (2), 136-159.

(36) Ioannides, M.; Fink, E.; M, W.; Hutchison, D.; Kersten, T. P.; Tschirschwitz, F.; Deggim, S.; Lindstaedt, M. Digital Heritage. Progress in Cultural Heritage: Documentation, Preservation, and Protection; Ioannides, M., Fink, E., Brumana, R., Patias, P., Doulamis, A., Martins, J., Wallace, M., Eds.; Lecture Notes in Computer Science; Springer International Publishing: Cham, 2018; Vol. 11197. DOI: 10.1007/ 978-3-030-01765-1.

(37) Andersen, S. A. W.; Mikkelsen, P. T.; Konge, L.; CayéThomasen, P.; Sørensen, M. S. Cognitive Load in Mastoidectomy Skills Training: Virtual Reality Simulation and Traditional Dissection Compared. J. Surg. Educ. 2016, 73 (1), 45-50.

(38) Moran, J.; Briscoe, G.; Peglow, S. Current Technology in Advancing Medical Education: Perspectives for Learning and Providing Care. Acad. Psychiatry 2018, 42 (6), 796-799.

(39) Guo, Y.; Mao, L.; Zhang, G.; Chen, Z.; Pei, X.; Xu, X. G. Conceptual Design and Preliminary Results of A VR-Based Radiation Safety Training System for Interventional Radiologists. Radiat. Prot. Dosim. 2020, 190, 58.

(40) Bogusevschi, D.; Muntean, C. H.; Muntean, G. Teaching and Learning Physics Using 3D Virtual Learning Environment: A Case Study of Combined Virtual Reality and Virtual Laboratory in Secondary. Proc. Soc. Inf. Technol. Teach. Educ. Int. Conf. 2019, 721-728.

(41) Psotka, J. Games and Virtual Reality as Disruptive Technologies. Int. Forum Educ. Technol. Soc. 2013, 16 (2), 69-80.

(42) Vrellis, I.; Papachristos, N. M.; Bellou, J.; Avouris, N.; Mikropoulos, T. A. Designing a Collaborative Learning Activity in Second Life - An Exploratory Study in Physics. In 2010 10th IEEE International Conference on Advanced Learning Technologies; IEEE, 2010; pp 210-214. DOI: 10.1109/ICALT.2010.65.

(43) De Lucia, A.; Francese, R.; Passero, I.; Tortora, G. Development and Evaluation of a System Enhancing Second Life to Support Synchronous Role-Based Collaborative Learning. Softw. Pract. Exp. 2009, 39 (12), 1025-1054.

(44) Sekaran, S. C.; Yap, H. J.; Liew, K. E.; Kamaruzzaman, H.; Tan, C. H.; Rajab, R. S. Haptic-Based Virtual Reality System to Enhance Actual Aerospace Composite Panel Drilling Training; Elsevier, 2018. DOI: 10.1016/B978-0-08-102291-7.00007-1.

(45) Buttussi, F.; Chittaro, L. Effects of Different Types of Virtual Reality Display on Presence and Learning in a Safety Training Scenario. IEEE Trans. Vis. Comput. Graph. 2018, 24 (2), 1063-1076.

(46) Leder, J.; Horlitz, T.; Puschmann, P.; Wittstock, V.; Schütz, A. Comparing Immersive Virtual Reality and PowerPoint as Methods for 
Delivering Safety Training: Impacts on Risk Perception, Learning, and Decision Making. Saf. Sci. 2019, 111, 271-286.

(47) Avveduto, G.; Tanca, C.; Lorenzini, C.; Tecchia, F.; Carrozzino, M.; Bergamasco, M. Safety Training Using Virtual Reality: A Comparative Approach. In Lecture Notes in Computer Science (including subseries Lecture Notes in Artificial Intelligence and Lecture Notes in Bioinformatics); LNCS, 2017; Vol. 10324, pp 148163. DOI: $10.1007 / 978-3-319-60922-511$.

(48) Grigoleit, T.; Silva, H.; Burress, $\bar{M}$. A.; Chiappe, D. Toward a Descriptive Measure of Situation Awareness in Petrochemical Refining. In Advances in Human Factors in Energy: Oil, Gas, Nuclear and Electric Power Industries, Advances in Intelligent Systems and Computing; Cetiner, S. M., Fechtelkotter, P., Legatt, M., Eds.; Springer International Publishing: Cham, 2017; pp 3-14. DOI: 10.1007/9783-319-41950-3 1.

(49) Reid, C. R.; Schall, M. C.; Amick, R. Z.; Schiffman, J. M.; Lu, M. L.; Smets, M.; Moses, H. R.; Porto, R. Wearable Technologies: How Will We Overcome Barriers to Enhance Worker Performance, Health, and Safety? Proc. Hum. Factors Ergon. Soc. 2017, 61, 10261030.

(50) Nakai, A.; Kaihata, Y.; Suzuki, K. The Experience-Based Safety Training System Using Vr Technology for Chemical Plant. Int. J. Adv. Comput. Sci. Appl. 2014, 5 (11), 63-67.

(51) Helin, K., D'Cruz, M., Eds. Joint VR Conference of EuroVR and EGVE, 2011/Current and Future Perspectives of Virtual Reality, Augmented Reality and Mixed Reality: Industrial and Poster Track. In VTT Symposium (Valtion Teknillinen Tutkimuskeskus); VTT: Nottingham, 2011; pp 20-26.

(52) Cheng, S.; Chen, G.; Chen, Q.; Xiao, X. Research on 3D Dynamic Visualization Simulation System of Toxic Gas Diffusion Based on Virtual Reality Technology. Process Saf. Environ. Prot. 2009, 87 (3), 175-183.

(53) Feng, Z.; González, V. A.; Trotter, M.; Spearpoint, M.; Thomas, J.; Ellis, D.; Lovreglio, R. How People Make Decisions during Earthquakes and Post-Earthquake Evacuation: Using Verbal Protocol Analysis in Immersive Virtual Reality. Saf. Sci. 2020, 129, 104837.

(54) Duan, X.; Kang, S. J.; Choi, J. I.; Kim, S. K. Mixed Reality System for Virtual Chemistry Lab. KSII Trans. Internet Inf. Syst. 2020, 14 (4), 1673-1688.

(55) Cassidy, K. C.; Šefćík, J.; Raghav, Y.; Chang, A.; Durrant, J. D. ProteinVR: Web-Based Molecular Visualization in Virtual Reality. PLoS Comput. Biol. 2020, 16 (3), e1007747.

(56) Bennie, S. J.; Ranaghan, K. E.; Deeks, H.; Goldsmith, H. E.; O'Connor, M. B.; Mulholland, A. J.; Glowacki, D. R. Teaching Enzyme Catalysis Using Interactive Molecular Dynamics in Virtual Reality. J. Chem. Educ. 2019, 96 (11), 2488-2496.

(57) Ferrell, J. B.; Campbell, J. P.; McCarthy, D. R.; McKay, K. T.; Hensinger, M.; Srinivasan, R.; Zhao, X.; Wurthmann, A.; Li, J.; Schneebeli, S. T. Chemical Exploration with Virtual Reality in Organic Teaching Laboratories. J. Chem. Educ. 2019, 96 (9), 19611966

(58) Xu, K.; Liu, N.; Xu, J.; Guo, C.; Zhao, L.; Wang, H.; Zhang, Q. C. VRmol: An Integrative Cloud-Based Virtual Reality System to Explore Macromolecular Structure. bioRxiv, 2019, 589366. DOI: $10.1101 / 589366$

(59) Amabilino, S.; Bratholm, L. A.; Bennie, S. J.; Vaucher, A. C.; Reiher, M.; Glowacki, D. R. Training Neural Nets To Learn Reactive Potential Energy Surfaces Using Interactive Quantum Chemistry in Virtual Reality. J. Phys. Chem. A 2019, 123 (20), 4486-4499.

(60) O’Connor, M. B.; Bennie, S. J.; Deeks, H. M.; Jamieson-Binnie, A.; Jones, A. J.; Shannon, R. J.; Walters, R.; Mitchell, T. J.; Mulholland, A. J.; Glowacki, D. R. Interactive Molecular Dynamics in Virtual Reality from Quantum Chemistry to Drug Binding: An OpenSource Multi-Person Framework. J. Chem. Phys. 2019, 150 (22), 220901.

(61) O'Connor, M.; Deeks, H. M.; Dawn, E.; Metatla, O.; Roudaut, A.; Sutton, M.; Thomas, L. M.; Glowacki, B. R.; Sage, R.; Tew, P.; Wonnacott, M.; Bates, P.; Mulholland, A. J.; Glowacki, D. R. Sampling
Molecular Conformations and Dynamics in a Multiuser Virtual Reality Framework. Sci. Adv. 2018, 4 (6), eaat2731.

(62) Winkelmann, K.; Keeney-Kennicutt, W.; Fowler, D.; Macik, M. Development, Implementation, and Assessment of General Chemistry Lab Experiments Performed in the Virtual World of Second Life. J. Chem. Educ. 2017, 94 (7), 849-858.

(63) Ullah, S.; Ali, N.; Rahman, S. U. The Effect of Procedural Guidance on Students' Skill Enhancement in a Virtual Chemistry Laboratory. J. Chem. Educ. 2016, 93 (12), 2018-2025.

(64) Makransky, G.; Thisgaard, M. W.; Gadegaard, H. Virtual Simulations as Preparation for Lab Exercises: Assessing Learning of Key Laboratory Skills in Microbiology and Improvement of Essential Non-Cognitive Skills. PLoS One 2016, 11 (6), e0155895.

(65) Norrby, M.; Grebner, C.; Eriksson, J.; Boström, J. Molecular Rift: Virtual Reality for Drug Designers. J. Chem. Inf. Model. 2015, 55 (11), 2475-2484.

(66) Dunnagan, C. L.; Dannenberg, D. A.; Cuales, M. P.; Earnest, A. D.; Gurnsey, R. M.; Gallardo-Williams, M. T. Production and Evaluation of a Realistic Immersive Virtual Reality Organic Chemistry Laboratory Experience: Infrared Spectroscopy. J. Chem. Educ. 2020, 97 (1), 258-262.

(67) Keeney-Kennicutt, W. L.; Merchant, Z. H. Using Virtual Worlds in the General Chemistry Classroom. ACS Symp. Ser. 2013, 1142, 181-204.

(68) Saleh, T. A. Testing the Effectiveness of Visual Aids in Chemical Safety Training. J. Chem. Health Saf. 2011, 18 (2), 3-8.

(69) Deeks, H. M.; Walters, R. K.; Hare, S. R.; O’Connor, M. B.; Mulholland, A. J.; Glowacki, D. R. Interactive Molecular Dynamics in Virtual Reality for Accurate Flexible Protein-Ligand Docking. PLoS One 2020, 15 (3), e0228461.

(70) Doak, D. G.; Denyer, G. S.; Gerrard, J. A.; Mackay, J. P.; Allison, J. R. Peppy: A Virtual Reality Environment for Exploring the Principles of Polypeptide Structure. Protein Sci. 2020, 29 (1), 157168.

(71) Tian, Y.; Fu, H.; Liu, J.; Wang, L.; Xu, X. Virtual Reality Educational Tool for Connecting Chemistry Lecture with Remote Laboratory Demonstrations. ChemRxiv, 2020, 12040173.V1. DOI: 10.26434/CHEMRXIV.12040173.V1.

(72) Laureanti, J.; Brandi, J.; Offor, E.; Engel, D.; Rallo, R.; Ginovska, B.; Martinez, X.; Baaden, M.; Baker, N. A. Visualizing Biomolecular Electrostatics in Virtual Reality with UnityMol-APBS. Protein Sci. 2020, 29 (1), 237-246.

(73) Davison, T.; Samavati, F.; Jacob, C. Computers \& Graphics LifeBrush : Painting, Simulating, and Visualizing Dense Biomolecular Environments. Comput. Graph. 2019, 82, 232-242.

(74) Ferrell, J. B.; Campbell, J. P.; McCarthy, D. R.; McKay, K. T.; Hensinger, M.; Srinivasan, R.; Zhao, X.; Wurthmann, A.; Li, J.; Schneebeli, S. T. Chemical Exploration with Virtual Reality in Organic Teaching Laboratories. J. Chem. Educ. 2019, 96 (9), 19611966.

(75) Kingsley, L. J.; Brunet, V.; Lelais, G.; McCloskey, S.; Milliken, K.; Leija, E.; Fuhs, S. R.; Wang, K.; Zhou, E.; Spraggon, G. Development of a Virtual Reality Platform for Effective Communication of Structural Data in Drug Discovery. J. Mol. Graphics Modell. 2019, 89, 234-241.

(76) Johnstone, A. H.; Wham, A. The Demands of Practical Work. Educ. Chem. 1982, 19, 71-73.

(77) Garratt, J. Virtual Investigations: Ways to Accelerate Experience. Univ. Chem. Educ. 1997, 1 (1), 19-27.

(78) Smith, D. K. From Crazy Chemists to Engaged Learners through Education. Nat. Chem. 2011, 3, 681-684.

(79) Johnstone, A. H.; Sleet, R. J.; Vianna, J. F. An Information Processing Model of Learning: Its Application to an Undergraduate Laboratory Course in Chemistry. Stud. High. Educ. 1994, 19 (1), 7787.

(80) Winberg, T. M.; Berg, C. A. R. Students' Cognitive Focus during a Chemistry Laboratory Exercise: Effects of a ComputerSimulated Prelab. J. Res. Sci. Teach. 2007, 44 (8), 1108-1133. 
(81) Spagnoli, D.; Wong, L.; Maisey, S.; Clemons, T. D. Prepare, Do, Review: A Model Used to Reduce the Negative Feelings towards Laboratory Classes in an Introductory Chemistry Undergraduate Unit. Chem. Educ. Res. Pract. 2017, 18 (1), 26-44.

(82) Pekdağ, B. Video-Based Instruction on Safety Rules in the Chemistry Laboratory: Its Effect on Student Achievement. Chem. Educ. Res. Pract. 2020, 21 (2013), 953-968.

(83) Hill, D. J.; Williams, O. F.; Mizzy, D. P.; Triumph, T. F.; Brennan, C. R.; Mason, D. C.; Lawrence, D. S. Introduction to Laboratory Safety for Graduate Students: An Active-Learning Endeavor. J. Chem. Educ. 2019, 96 (4), 652-659.

(84) Fung, F. M. Using First-Person Perspective Filming Techniques for a Chemistry Laboratory Demonstration to Facilitate a Flipped PreLab. J. Chem. Educ. 2015, 92 (9), 1518-1521.

(85) Hesser, T. L. Web Based Classes for Enhancement of Pre Laboratory Lecture. ASEE Annual Conference and Exposition, Conference Proceedings 2009, 1360.

(86) Pope, D. P.; Anderson, H. L. Reducing the Costs of Laboratory Instruction through the Use of On-Line Laboratory Instruction. Mater. Res. Soc. Symp. Proc. 2001, 117-122.

(87) Nazir, S.; Sorensen, L. J.; Øvergård, K. I.; Manca, D. Impact of Training Methods on Distributed Situation Awareness of Industrial Operators. Saf. Sci. 2015, 73, 136-145.

(88) Ilieva, N.; Boiadjieva, E. Assessment of the Perceptions of the Learning Environment in University Groups. Chemistry (Easton) 2016, 25 (1), 137-153.

(89) Bailey, J.; Bailenson, J.; Won, A.; Flora, J.; Armel, K. Presence and Memory: Immersive Virtual Reality Effects on Cued Recall. Proceedings of the International Society for Presence Research Annual Conference 2011, 24-26.

(90) Makransky, G.; Terkildsen, T. S.; Mayer, R. E. Adding Immersive Virtual Reality to a Science Lab Simulation Causes More Presence but Less Learning. Learn. Instr. 2019, 60, 225-236.

(91) Grassini, S.; Laumann, K.; Rasmussen Skogstad, M. The Use of Virtual Reality Alone Does Not Promote Training Performance (but Sense of Presence Does). Front. Psychol. 2020, 11, 1743.

(92) Ai-Lim Lee, E.; Wong, K. W.; Fung, C. C. How Does Desktop Virtual Reality Enhance Learning Outcomes? A Structural Equation Modeling Approach. Comput. Educ. 2010, 55 (4), 1424-1442.

(93) Lessiter, J.; Freeman, J.; Keogh, E.; Davidoff, J. A Cross-Media Presence Questionnaire: The ITC-Sense of Presence Inventory. Presence Teleoperators Virtual Environ. 2001, 10 (3), 282-297.

(94) Lewis, J. R. The System Usability Scale: Past, Present, and Future. Int. J. Human-Computer Interact. 2018, 34 (7), 577-590.

(95) Brooke, J.SUS-A Quick and Dirty Usability Scale. In Usability Evaluation In Industry; Jordan, P. W., Thomas, B., McClelland, I. L., Weerdmeester, B., Eds.; Taylor \& Francis, 1996; p 18.

(96) MeasuringU: 5 Ways to Interpret a SUS Score. https:// measuringu.com/interpret-sus-score/ (accessed July 30, 2020).

(97) MeasuringU: 10 Things to Know About the System Usability Scale (SUS). https://measuringu.com/10-things-sus/ (accessed July 30, 2020).

(98) PSPP-GNU Project-Free Software Foundation. https://www. gnu.org/software/pspp/ (accessed July 30, 2020).

(99) Pennebaker, J. W.; Boyd, R. L.; Jordan, K.; Blackburn, K. The Development and Psychometric Properties of LIWC2015. Austin, TX Univ. Texas Austin 2015, 1-22.

(100) Chung, C. K.; Pennebaker, J. W. Linguistic Inquiry and Word Count (LIWC). In Applied Natural Language Processing; IGI Global, 2012; pp 206-229. DOI: 10.4018/978-1-60960-741-8.ch012.

(101) Tausczik, Y. R.; Pennebaker, J. W. The Psychological Meaning of Words: LIWC and Computerized Text Analysis Methods. J. Lang. Soc. Psychol. 2010, 29 (1), 24-54.

(102) Washington, J. B. Scotland PhD Competition winner Jack Washington talks antibiotic resistance. https://www.soci.org/news/ scotland/scotland-phd-competition-winner-jack-washington-talksantibiotic-resistance (accessed July 24, 2020).

(103) Saudagar, P. S.; Survase, S. A.; Singhal, R. S. Clavulanic Acid: A Review. Biotechnol. Adv. 2008, 26 (4), 335-351.
(104) Rutherford, C. Irvine pharmaceutical firm fined $£ 55,000$ after explosion injures two employees. https://www.dailyrecord.co.uk/news/ local-news/irvine-pharmaceutical-firm-fined-55000-9495002 (accessed July 24, 2020).

(105) Two suffer burns in factory blast. http://news.bbc.co.uk/1/hi/ scotland/4765444.stm (accessed July 24, 2020).

(106) MacFarlane, D. R.; Cherepanov, P. V.; Choi, J.; Suryanto, B. H. R.; Hodgetts, R. Y.; Bakker, J. M.; Ferrero Vallana, F. M.; Simonov, A. N. A Roadmap to the Ammonia Economy. Joule 2020, 4 (6), $1186-1205$.

(107) Service, R. Ammonia-a renewable fuel made from sun, air, and water-could power the globe without carbon. http://www.sciencemag. org/news/2018/07/ammonia-renewable-fuel-made-sun-air-andwater-could-power-globe-without-carbon (accessed July 24, 2020). DOI: $10.1126 /$ science.aau 7489 .

(108) Chan, J. Two dead in ammonia leak at Petronas plant|Malaysial Malay Mail. https://www.malaymail.com/news/malaysia/2016/08/ 16/two-dead-in-ammonia-leak-at-petronas-plant/1184521 (accessed July 24, 2020).

(109) Anhydrous Ammonia Millard Refrigeration (Theodore, $A L$, 2010)|AIChE-PSID Incident Report. http://www3.aiche.org/PSID/ Reports/IncidentReport.aspx (accessed July 24, 2020).

(110) Ziegler, R. Office of the Illinois Attorney General-Seward Ammonia Leak. https://illinoisattorneygeneral.gov/pressroom/2007_ 05/20070511.html (accessed July 24, 2020).

(111) Ammonia Tank Failure (Lithuania, 1989)|AIChE-PSID Incident Report. http://www3.aiche.org/PSID/Reports/IncidentReport.aspx (accessed July 24, 2020).

(112) Georgia-Based Millard Refrigerated Services to Pay \$3 Million Civil Penalty for Ammonia Release That Sickened Workers Responding to Deepwater Horizon Oil SpillIOPAIDepartment of Justice. https://www. justice.gov/opa/pr/georgia-based-millard-refrigerated-services-pay-3million-civil-penalty-ammonia-release (accessed July 28, 2020).

(113) Vessel Explosion (Louisville, KY, 2003)|AIChE-PSID Incident Report. http://www3.aiche.org/PSID/Reports/IncidentReport.aspx (accessed July 24, 2020).

(114) 3 towns evacuated after ammonia leak. https://www. yourlawyer.com/environmental-cases/towns-evacuated-ammonialeak/ (accessed July 24, 2020).

(115) Mahle plant ammonia leak prompts Kilmarnock evacuation. https://www.bbc.co.uk/news/uk-scotland-glasgow-west-12156181 (accessed July 24, 2020).

(116) Lilydale to pay \$180K for 2009 ammonia leak. https://www. cbc.ca/news/canada/calgary/lilydale-to-pay-180k-for-2009-ammonialeak-1.1232080 (accessed July 24, 2020).

(117) Old, J. Company faces criminal charge in 2009 ammonia leak that killed woman. https://www.wistv.com/story/21045620/ company-faces-criminal-charge-in-2009-ammonia-leak-that-killedwoman/ (accessed July 24, 2020).

(118) Melbourne meat plant ammonia leak contained. https://www. abc.net.au/news/2014-03-17/melbourne-meat-plant-evacuated-overammonia-leak/5325974 (accessed July 24, 2020).

(119) O'Halloran, S. Fire, ammonia leak shut down Cargill beef plant 2014-02-07|Food Engineering. https://www.foodengineeringmag. com/articles/91912-fire-ammonia-leak-shut-down-cargill-beef-plant (accessed July 24, 2020).

(120) Fecke, M.; Garner, S.; Cox, B. Review of Global Regulations for Anhydrous Ammonia Production, Use, and Storage. Hazards 2016, 26, 161.

(121) Seward ammonia spill (part 1). https://www.youtube.com/ watch? $=$ =sNkdAsle7Cw (accessed July 24, 2020).

(122) McWhinnie, S. The Finances of Chemistry and Physics Departments in UK Universities: Third Review; IOP, 2015.

(123) Goudarzi, S. A More Holistic Approach to Laboratory Resource Reduction. https://www.labmanager.com/business-management/amore-holistic-approach-to-laboratory-resource-reduction-2253 (accessed September 4, 2020). 